\title{
Synthesis and bulk polymerization kinetics of monomer dehydroabietic acid-(2-acryloyloxy-ethoxy)-ethyl ester
}

\author{
Haibo ZHANG ${ }^{1}$, Yanping YANG ${ }^{1}$, He LIU ${ }^{1}$, Jie SONG ${ }^{2}$, Shibin SHANG $(\bowtie)^{1,3}$, Zhanqian SONG ${ }^{1,3}$ \\ 1 National Engineering Laboratory for Biomass Chemical Utilization; Key and Open Laboratory of Forest Chemical Engineering, \\ State Forestry Administration; Key Laboratory of Biomass Energy and Material, Institute of Chemical Industry of Forest Products, \\ Chinese Academy of Forestry, Nanjing 210042, China \\ 2 Department of Chemistry and Biochemistry, University of Michigan-Flint, Michigan 48502, USA \\ 3 Institute of New Technology of Forestry, Chinese Academy of Forestry, Beijing 100091, China
}

\begin{abstract}
A bulk polymerization monomer dehydroabietic acid-(2-acryloyloxy-ethoxy)-ethyl ester (DHADG-AC) was synthesized from dehydroabietic acid (DHA). The chemical structure of DHA-DG-AC was characterized by ${ }^{1} \mathrm{H}$ NMR, ${ }^{13} \mathrm{C}$ NMR, MS and FT-IR. The kinetics of the bulk polymerization of DHA-DG-AC was investigated by Differential Scanning Calorimeter (DSC). Two kinds of kinetic model (nth-order model and autocatalytic model) were used to investigate the polymerization process. The results showed that the experimental DSC curves were consistent with the computational data generated by the autocatalytic kinetic model, and the value of $E_{\mathrm{a}}$ was $95.73 \mathrm{~kJ} \cdot \mathrm{mol}^{-1}$.
\end{abstract}

Keywords dehydroabietic acid, bulk polymerization, kinetics, autocatalytic kinetic model

\section{Introduction}

With the limitations in sourcing fossil fuels and the aggravation of environmental pollution, biomass resources such as rosin and oil are becoming more attractive ${ }^{[1]}$. Biomass resources are widely used to replace petrochemical resources, especially for polymers ${ }^{[1,2]}$. Hence, the design and synthesis of a naturally-derived polymerizable monomer is very important for sustainable development $^{[3,4]}$.

Rosin is an abundant renewable resource which consists primarily of $90 \%$ rosin acids with characteristic hydrophenanthrene structures and $10 \%$ neutral compounds, and

Received July 13, 2016; accepted October 21, 2016

Correspondence: shangsb@hotmail.com is widely used in many fields such as paper making, paint, adhesives and rubber ${ }^{[5]}$. The major component of rosin acid is abietic acid with a molecular formula $\mathrm{C}_{20} \mathrm{H}_{30} \mathrm{O}_{2}$. Abietic acid possesses a basic molecular structure of one carboxyl group and conjugated double bonds, which can react with different chemical substances to be transformed in polymerizable monomers ${ }^{[6]}$. Abietic acid reacts with maleic anhydride, acrylic acid, fumaric acid to be produced maleopimaric acid ${ }^{[7,8]}$, acrylopimaric acid ${ }^{[9,10]}$, and fumaropimaric acid ${ }^{[11,12]}$ by the Diels-Alder reaction. The rosin based monomers can be used for further synthesis and to prepare polymers. Rosin based polymers, including epoxy resin $^{[13,14]}$, polyester ${ }^{[15,16]}$ and polyamide ${ }^{[17,18]}$, have been investigated as alternatives to petroleum based feedstock, as these exhibit better thermal stability and chemical resistance than petro-based polymers.

Vinyl, acrylic and allyl ester groups, which can undergo radical polymerization, have been grafted onto the rosin acid structure to afford rosin-derived vinyl polymeric monomers ${ }^{[19,20]}$. However, only a few applications of rosin-derived vinyl monomers have been reported, including use as crosslinking agent in UV-polymerization and thermal polymerization ${ }^{[21,22]}$. Due to characteristic hydrophenanthrene structures, rosin-derived vinyl monomers are used to synthesize pressure-sensitive adhesives with a high glass transition temperature and better adhesion performance by copolymerization with acrylic ester monomers $^{[23]}$, and have great potential to be used in hydrophobically-modified water-soluble polymers. An appropriate kinetic model is one important prerequisite for understanding of polymerization. Such models are not only possible to predict the extent of polymerization, but they can also be used for process optimization in different systems $^{[24]}$.

Differential scanning calorimetry (DSC) is the most widely used method to measure kinetic parameters, such as 
heat flow, extent of conversion and rate of conversion. A kinetic equation can then be used to compare with experimental data obtained by DSC. The study of cure kinetics of thermosetting polymers is useful for understanding the relationship between structure and properties $^{[25]}$. Um et al. ${ }^{[26]}$ proposed a procedure manipulating dynamic scanning data to determine cure kinetics, and then the cure kinetics were applied to study a three-component epoxy resin system. For free radical polymerization, several theories have been proposed to explain the kinetics and have achieved varying degrees of success in fitting the experimental data ${ }^{[27,28]}$. Zhang et al. ${ }^{[29]}$ studied the kinetics of polymerization of 2,2-dinitropropyl acrylate, 2,2-dinitrobutyl acrylate and 2,2-dinitrobutyl methacrylate, which showed that the polymerization ability of three monomers decreased due to the presence of substituent methyl groups on the acrylyl double bond and 2,2dinitrobutyl on the ester group.

In this paper, a new radical polymerization monomer dehydroabietic acid-(2-acryloyloxy-ethoxy)-ethyl ester (DHA-DG-AC) was synthesized from dehydroabietic acid (DHA) which was separated from rosin. The kinetics were investigated by differential scanning calorimeter (DSC) in the non-isothermal mode and compared to the computational kinetic data. DHA-DG-AC has been shown to be a naturally-derived bulk polymerizable monomer.

\section{Materials and methods}

\subsection{Materials}

DHA (purity $95 \%$, melting point $165-167^{\circ} \mathrm{C}$ ) was separated from rosin according to published literature ${ }^{[30]}$. Oxalyl chloride, 4-dimethylaminopyridine, pyridine, triethylamine, 4-methoxyphenol, diethylene glycol, acrylylchloride and azodiisobutyronitrile were purchased from Aladdin Industrial Corporation (China, Shanghai) and used without further purification.

2.2 Synthesis of dehydroabietic acid-(2-hydroxy-ethoxy)ethyl ester

DHA (3.00 g, $0.01 \mathrm{~mol}$ ) was dissolved in dichloromethane in an ice water bath, oxalyl chloride $(1.51 \mathrm{~g}, 0.012 \mathrm{~mol})$ was added dropwise into the flask. The mixture was stirred at $25^{\circ} \mathrm{C}$ for $4 \mathrm{~h}$. After the reaction, the excessive oxalyl chloride and dichloromethane were removed in a rotary evaporator to yield synthesized dehydroabietic acid chloride (DHA-Cl). The DHA-Cl was then dissolved in dichloromethane. The mixture of diethylene glycol $(5.3 \mathrm{~g}$, $0.05 \mathrm{~mol})$, 4-dimethylaminopyridine $(6.1 \mathrm{~g}, 0.05 \mathrm{~mol})$, pyridine $(0.79 \mathrm{~g}, 0.01 \mathrm{~mol})$ and dichloromethane was added dropwise into the DHA-Cl solution in an ice water bath. The mixture was then heated to $40^{\circ} \mathrm{C}$ for $12 \mathrm{~h}$. After the reaction, the organic phase was washed three times with dilute hydrochloric acid and three times with deionized water, dried with anhydrous sodium sulfate. The solvent was evaporated under vacuum to yield a yellow viscous liquid, dehydroabietic acid-(2-hydroxyethoxy)-ethyl ester (DHA-DG, purity 95\%). DHA-DG, ${ }^{1} \mathrm{H}$ NMR $\left(\mathrm{CDCl}_{3}, \delta \mathrm{ppm}\right) 7.37-7.06(\mathrm{~m}, 1 \mathrm{H} ; \mathrm{Ar}-\mathrm{H}), 6.97$ (dd, 1H; Ar-H), 6.88 (s, 1H; Ar-H), 4.57-4.03 (m, 2H; $\left.\mathrm{COOCH}_{2}\right), 3.88-3.33\left(\mathrm{~m}, 6 \mathrm{H} ; \mathrm{OCH}_{2}\right), 3.02-2.61$ (m, 3H; $\left.\mathrm{CH}, \mathrm{CH}_{2}\right), 2.50-0.64\left(\mathrm{~m}, 22 \mathrm{H} ; \mathrm{CH}, \mathrm{CH}_{2}, \mathrm{CH}_{3}\right)$. FT-IR $\left(\mathrm{cm}^{-1}\right) 750,822,885(\mathrm{Ar}) ; 1124,1174,1245\left(\mathrm{CH}_{2} \mathrm{OCH}_{2}\right)$; 1458, 1497, 1611 (Ar); $1723\left(\mathrm{COOCH}_{2}\right) ; 2869,2954$ $\left(\mathrm{CH}_{3}, \mathrm{CH}_{2}\right)$ and $3435(\mathrm{OH})$.

\subsection{Synthesis of DHA-DG-AC}

The synthesized DHA-DG was used directly in the next step. DHA-DG (1.0 g, $0.0026 \mathrm{~mol})$, triethylamine (0.26 g), hydroquinone $(0.001 \mathrm{~g})$ and dichloromethane were mixed in a flask. The combined solution of acrylylchloride $(0.26 \mathrm{~g}, 0.0028 \mathrm{~mol})$ and dichloromethane was added dropwise into the flask, and then the mixture was stirred at $25^{\circ} \mathrm{C}$ for $12 \mathrm{~h}$. After the reaction, the solution was filtered and washed three times with $\mathrm{Na}_{2} \mathrm{CO}_{3}$ aqueous solution. The organic solution was vacuum-distilled at $400 \mathrm{~Pa}$ and $45^{\circ} \mathrm{C}$ and dried in a vacuum oven, and a transparent viscous liquid, DHA-DG-AC (purity 96\%), was obtained by silica gel column chromatography. DHA-DG-AC, ${ }^{1} \mathrm{H}$ NMR $\left(\mathrm{CDCl}_{3}, \delta \mathrm{ppm}\right) 7.53-7.13(\mathrm{~m}, 1 \mathrm{H} ; \mathrm{Ar}-\mathrm{H}), 7.04$ (dd, $1 \mathrm{H}$; Ar-H), $6.92(\mathrm{~s}, 1 \mathrm{H} ; \mathrm{Ar}-\mathrm{H}), 6.61-6.32\left(\mathrm{~m}, 1 \mathrm{H} ; \mathrm{CH}_{2}=\right.$ $\mathrm{CH}), 6.28-5.95\left(\mathrm{~m}, 1 \mathrm{H} ; \mathrm{CH}_{2}=\mathrm{CH}\right), 5.95-5.47(\mathrm{~m}, 1 \mathrm{H}$; $\left.\mathrm{CH}_{2}=\mathrm{CH}\right), 4.71-4.03\left(\mathrm{~m}, 4 \mathrm{H} ; \mathrm{COOCH}_{2}\right), 3.99-3.44(\mathrm{~m}$, $4 \mathrm{H} ; \mathrm{CH}_{2} \mathrm{OCH}_{2}$ ), 3.20-2.61 (m, 3H; $\mathrm{CH}, \mathrm{CH}_{2}$ ), 2.54-0.77 $\left(\mathrm{m}, 21 \mathrm{H} ; \mathrm{CH}, \mathrm{CH}_{2}, \mathrm{CH}_{3}\right) \cdot{ }^{13} \mathrm{C}$ NMR $\left(\mathrm{CDCl}_{3}, \delta \mathrm{ppm}\right)$ $177.98(\mathrm{C}=\mathrm{O}), 165.61(\mathrm{C}=\mathrm{O}), 146.37,145.22,134.22$, 126.41, 123.70, $123.42(\mathrm{Ar}) ; 130.57,127.69(\mathrm{C}=\mathrm{C})$; $68.68,68.43,63.13,62.88\left(\mathrm{OCH}_{2}\right) ; 47.15,44.30,37.45$, $36.46,36.057,32.96,29.63,24.71,23.49,23.47,21.24$, 18.09, $16.02\left(\mathrm{CH}_{2}, \mathrm{CH}_{3}, \mathrm{C}\right)$. FT-IR $\left(\mathrm{cm}^{-1}\right) 752,822,984$ (Ar); 1124, 1191, $1246\left(\mathrm{CH}_{2} \mathrm{OCH}_{2}\right) ; 1406,1456,1497$, $1619(\mathrm{Ar}) ; 1636\left(\mathrm{CH}_{2}=\mathrm{CH}\right), 1725\left(\mathrm{COOCH}_{2}\right)$ and 2869 , $2955\left(\mathrm{CH}_{3}, \mathrm{CH}_{2}\right)$. ESI-MS m/z $465.3[\mathrm{M}+\mathrm{Na}]^{+}$(Fig. S1).

\subsection{Measurement of the progress of bulk polymerization of DHA-DG-AC by differential scanning calorimeter}

DHA-DG-AC and 2 wt\% 2, 2'-azobis-isobutyronitrile were placed in a DSC cell. The kinetic data were obtained by DSC with nitrogen as flushing gas, heated from 25 to $200^{\circ} \mathrm{C}$ with different heating rates of 10,15 and $20 \mathrm{~K} \cdot \mathrm{min}^{-1}$. The heat flow was obtained, and then the kinetic data were processed further by DSC kinetics analysis software (Pyris Software, PerkinElmer, USA) to obtain the extent of conversion and the rate of polymerization. 


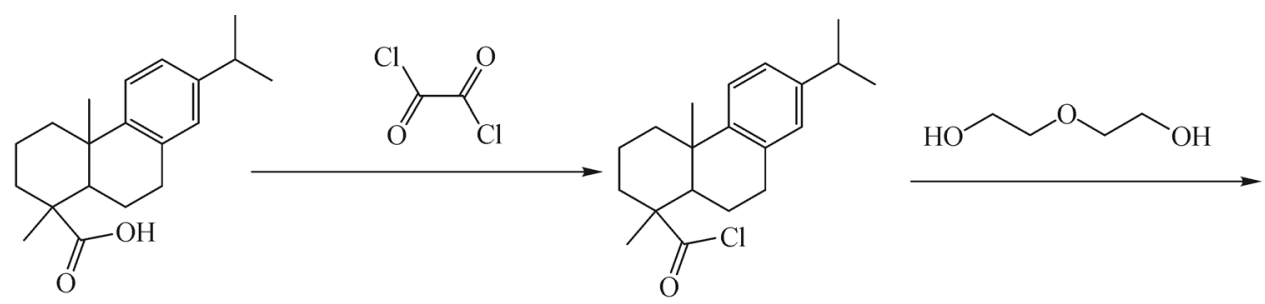

Dehydroabietic acid<smiles>CC(C)c1ccc2c(c1)CCC1C(C)(C(=O)OCCOCCO)CCCC21C</smiles>

Dehydroabietic acid-(2-hydroxy-ethoxy)-ethyl ester

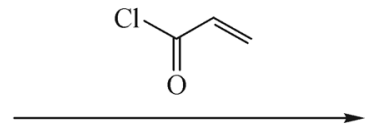

Dehydroabietic acid chloride

Fig. 1 Reaction scheme for synthesis of dehydroabietic acid-(2-acryloyloxy-ethoxy)-ethyl ester

\subsection{Characterization}

${ }^{1} \mathrm{H}$ NMR spectra were recorded with a Bruker $300 \mathrm{MHz}$ spectrometer at room temperature with deuterated chloroform. FT-IR spectra were obtained using a Thermo Scientific Nicolet iS10 FT-IR spectrometer (Thermo Fisher Scientific, Waltham, MA, USA) in the $400-4000 \mathrm{~cm}^{-1}$ wavenumber range. Mass spectrum was recorded on an Agilent-5973 spectrometer (ESI source; Agilent Technologies, Santa Clara, CA, USA).

\section{Results and discussion}

\subsection{Synthesis and characterization}

The synthetic of DHA-DG-AC is shown in Fig. 1. The FTIR spectra of DHA, DHA-DG and DHA-DG-AC are given in Fig. 2. In Fig. 2b, the characteristic DHA peak at $1687 \mathrm{~cm}^{-1}$ has disappeared after esterification, while peaks of ester carbonyl groups at $1725 \mathrm{~cm}^{-1}$ and hydroxyl group at $3435 \mathrm{~cm}^{-1}$ can be seen. In Fig. 2c, the characteristic peaks shown at $3435 \mathrm{~cm}^{-1}$ have disappeared and a peak at $1636 \mathrm{~cm}^{-1}$ indicates that the formation of the terminal $\mathrm{C}=$ $\mathrm{C}$ had occurred. The ${ }^{1} \mathrm{H}-\mathrm{NMR}$ spectra of DHA-DG and DHA-DG-AC are shown in Fig. 3. The signals from 6.8 to $7.5 \mathrm{ppm}$ were assigned to the protons on the aromatic ring. Compared to Fig. 3, the peaks from 5.5 to $6.6 \mathrm{ppm}$ represented the protons on the unsaturated carbon of acrylic ester group. In Fig. 4, the carboxyl groups at 177.98 and $165.61 \mathrm{ppm}$, and $\mathrm{C}=\mathrm{C}$ group at 130.57 and $127.69 \mathrm{ppm}$ are present. These peaks confirm that DHADG-AC was synthesized.

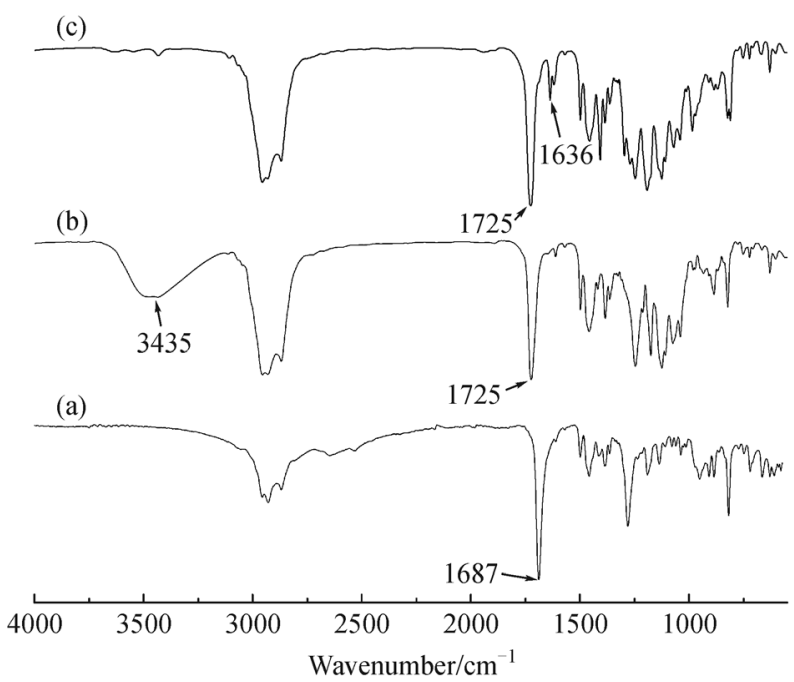

Fig. 2 FT-IR spectra of dehydroabietic acid (a), dehydroabietic acid-(2-hydroxy-ethoxy)-ethyl ester (b) and dehydroabietic acid(2-acryloyloxy-ethoxy)-ethyl ester (c)

\subsection{Model examination and data correlation}

The bulk polymerization kinetic parameters of DHA-DGAC were measured by DSC. It is assumed that the measured heat flow $(\mathrm{d} H / \mathrm{d} t)$ is proportional to the rate of polymerization $(\mathrm{d} \alpha / \mathrm{d} t)$. The rate of polymerization is defined as follows ${ }^{[31,32]}$ :

$$
\frac{\mathrm{d} \alpha}{\mathrm{d} t}=\frac{\mathrm{d} H}{\mathrm{~d} t} \times \frac{1}{\Delta H}
$$

where $\Delta H$ is the enthalpy of the polymerization reaction.

The rate of polymerization also can be described by 


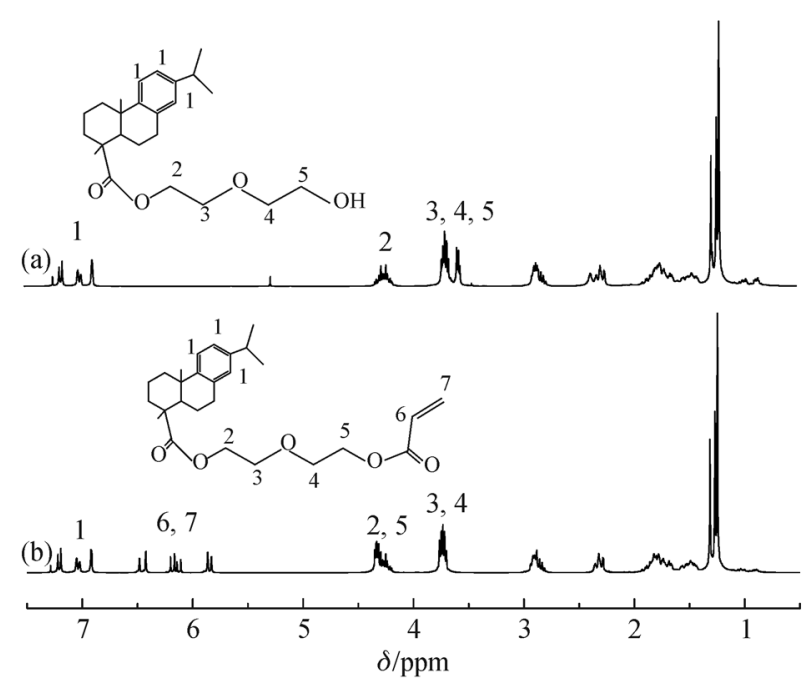

Fig. $3{ }^{1} \mathrm{H}$ NMR spectra of dehydroabietic acid-(2-hydroxyethoxy)-ethyl ester (a) and dehydroabietic acid-(2-acryloyloxyethoxy)-ethyl ester (b)

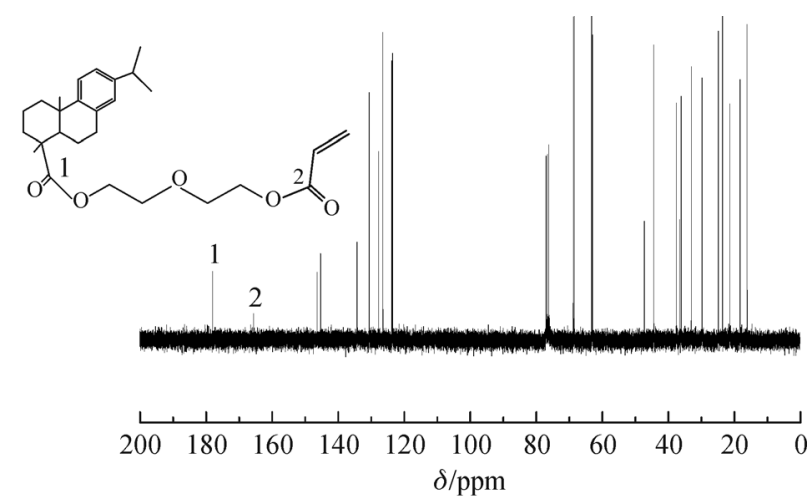

Fig. $4{ }^{13} \mathrm{C}$ NMR spectrum of dehydroabietic acid-(2-acryloyloxy-ethoxy)-ethyl ester

Eq. $2^{[33]}$ :

$$
\frac{\mathrm{d} \alpha}{\mathrm{d} t}=\mathrm{K}(T) \mathrm{f}(\alpha)
$$

where $\mathrm{f}(\alpha)$ is a dependent kinetic model function, and $\mathrm{K}(T)$ is the temperature-dependent rate constant dependent on Arrhenius relationship ${ }^{[34]}$.

$$
\mathrm{K}(T)=A \exp \left(-\frac{E_{\alpha}}{R T}\right)
$$

where $E_{\mathrm{a}}$ is the apparent activation energy, $A$ is the preexponential factor, $R$ is the gas constant and $T$ is the reaction temperature. The rate of polymerization is also obtained by Eqs. 2 and 3.

$$
\frac{\mathrm{d} \alpha}{\mathrm{d} t}=A \exp \left(-\frac{E_{\alpha}}{R T}\right) \mathrm{f}(\alpha)
$$

To develop a generalized model of the kinetics, two kinds of model (nth-order model and autocatalytic model) were investigated.

\subsubsection{Nth-order kinetic model}

For nth-order kinetic, $\mathrm{f}(\alpha)$ is described as follows.

$$
\mathrm{f}(\alpha)=(1-\alpha)^{n}
$$

where $n$ is the reaction order.

The rate of polymerization defined as follows is used.

$$
\frac{\mathrm{d} \alpha}{\mathrm{d} t}=A \exp \left(-\frac{E_{\alpha}}{R T}\right)(1-\alpha)^{n}
$$

The nth-order kinetic parameters are obtained by the Kissinger method ${ }^{[34]}$ and Crane method ${ }^{[35]}$. At the DSC peak exotherm $\left(T_{\mathrm{p}}\right)$, it is assumed that the extent of polymerization reaction is constant and not dependent on the heating rates $(\beta)$. The Kissinger method and the Crane method are shown in Eqs. 7 and 8.

$$
\begin{gathered}
\ln \frac{\beta}{T_{\mathrm{p}}^{2}}=\ln \left(\frac{A R}{E_{\alpha}}\right)-\frac{E_{\alpha}}{R T_{\mathrm{p}}} \\
\frac{\mathrm{d} \ln \beta}{\mathrm{d}\left(1 / T_{\mathrm{p}}\right)}=-\frac{E_{\alpha}}{n R}
\end{gathered}
$$

Figures 5-7 shows the DSC thermograms for the bulk polymerization of DHA-DG-AC measured at 10,15 and $20 \mathrm{~K} \cdot \mathrm{min}^{-1}$, and the value of $\ln \left(\beta / T_{\mathrm{p}}{ }^{2}\right)$ is given by the DSC peak exotherm. Figure 8 is $\ln \left(\beta / T_{\mathrm{p}}{ }^{2}\right)$ as a function of $1 / T_{\mathrm{p}}$. A linear relationship with the following equation was obtained.

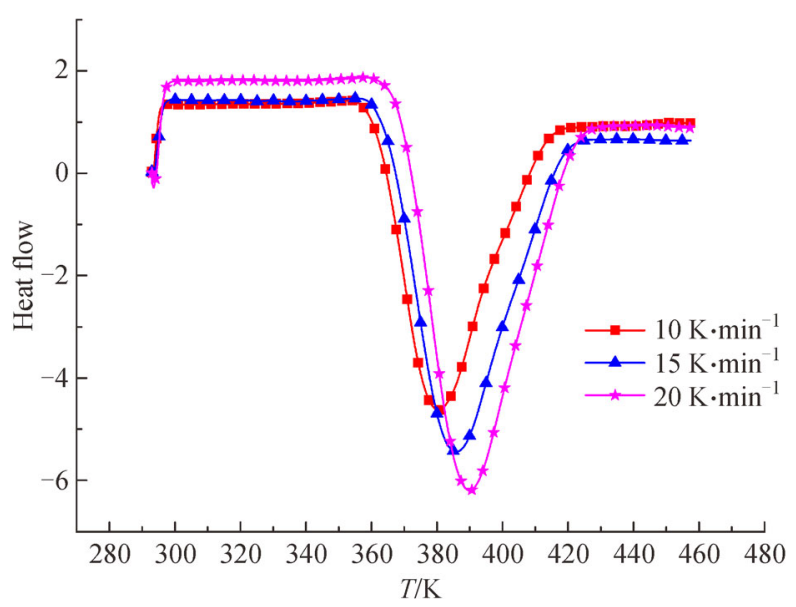

Fig. 5 DSC curves at different heating rates. $T$, the reaction temperature.

$$
\ln \frac{\beta}{T_{\mathrm{p}}^{2}}=-9954.93 \times \frac{1}{T_{\mathrm{p}}}+16.58
$$




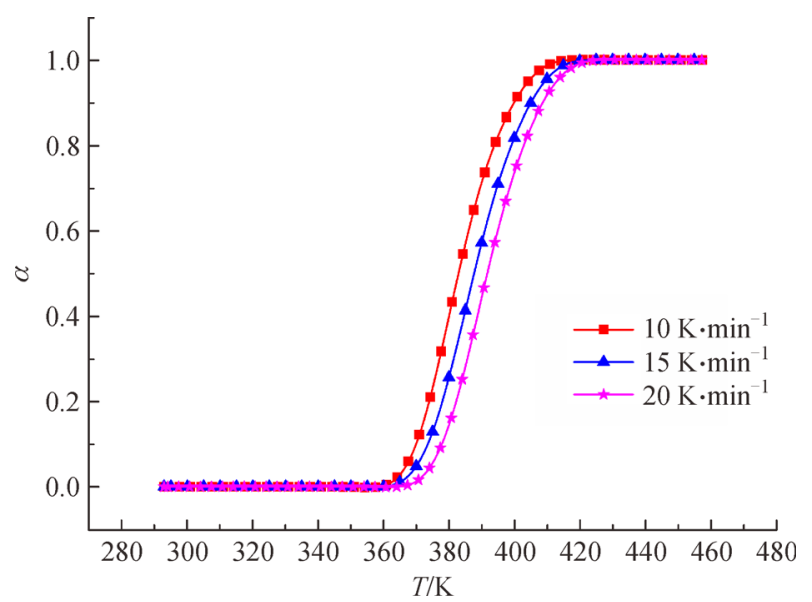

Fig. 6 Plots of $\alpha$ versus $T$ at different scan rates. $\alpha$, the conversion; $T$, the reaction temperature.

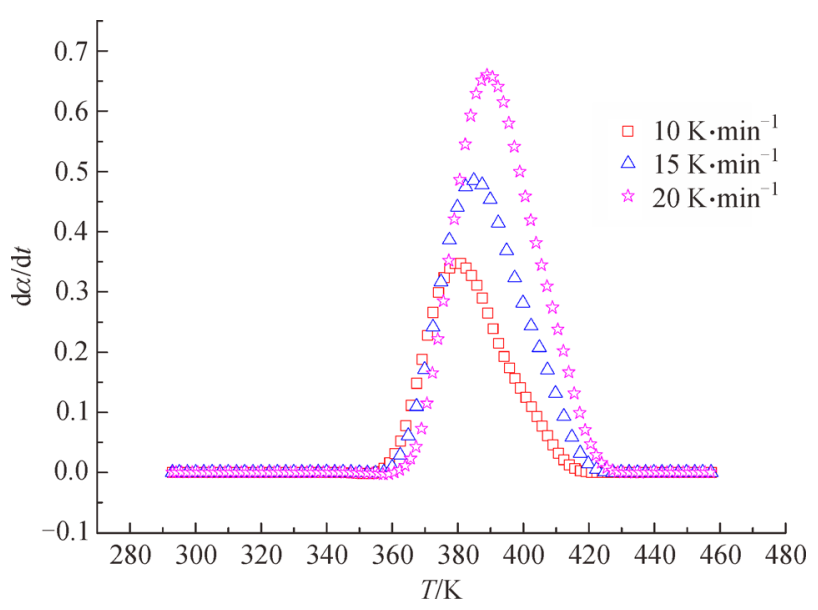

Fig. 7 Plots of $\mathrm{d} \alpha / \mathrm{d} t$ versus $T$ at different scan rates. $\mathrm{d} \alpha / \mathrm{d} t$, the rate of polymerization; $T$, the reaction temperature.

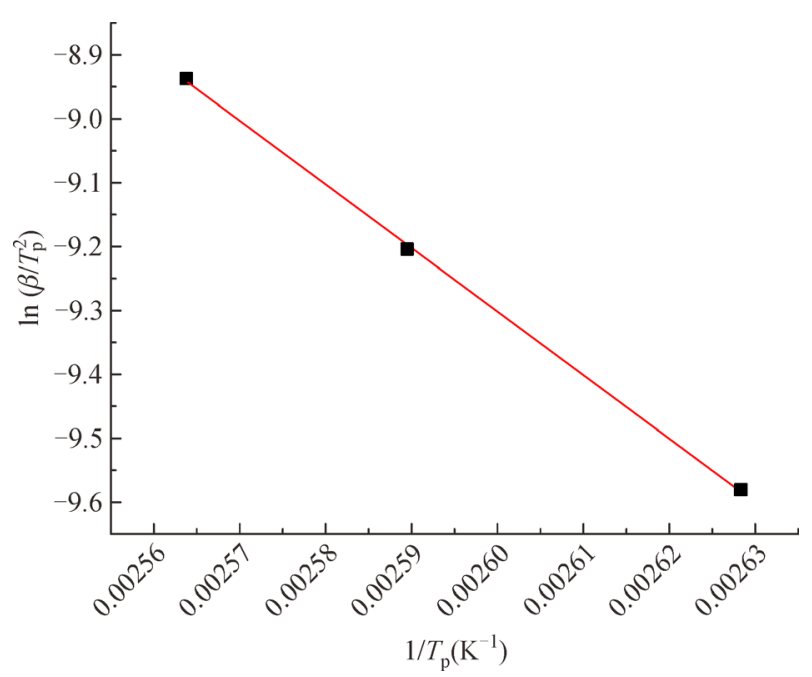

Fig. 8 Plots of $\ln \left(\beta / T_{\mathrm{p}}{ }^{2}\right)$ versus $1 / T_{\mathrm{p}} . \beta$, the heating rate; $T_{\mathrm{p}}$, the DSC peak exotherm.
Based on the slope and the intercept, the apparent activation energy $\left(E_{\mathrm{a}}\right)$ of $82.77 \mathrm{~kJ} \cdot \mathrm{mol}^{-1}$ was obtained and the pre-exponential factor A was $1.58 \times 10^{11}$. A linear relationship of $\ln (\beta)$ versus $1 / T_{\mathrm{p}}$ was obtained in Fig. 9 and the linear equation could be described by Eq. 10 .

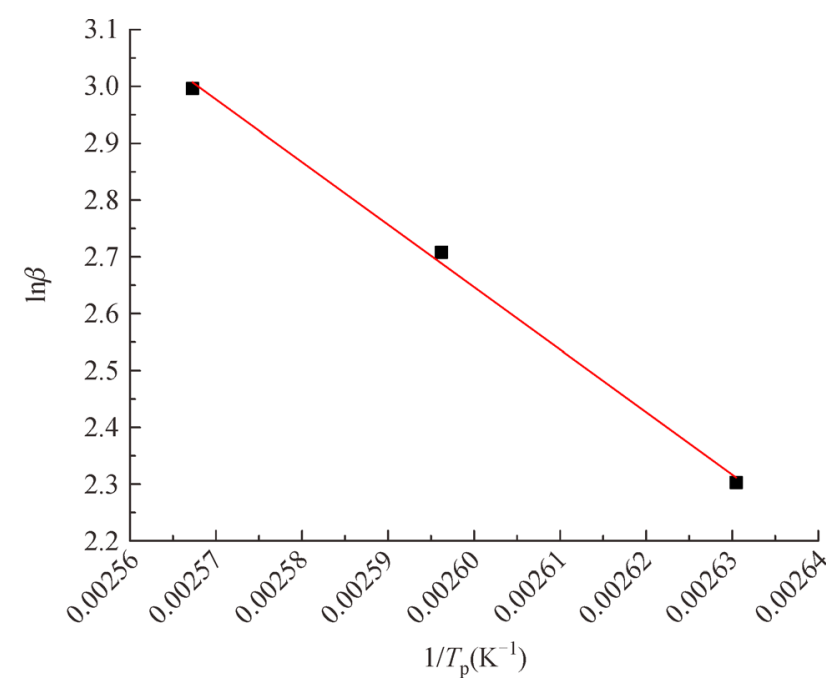

Fig. 9 Plots of $\ln \beta$ versus $1 / T_{\mathrm{p}} . \beta$, the heating rate; $T_{\mathrm{p}}$, the DSC peak exotherm.

$$
\ln \beta=-11003.73 \times \frac{1}{T_{\mathrm{p}}}+31.26
$$

From the slope and $E_{\mathrm{a}}$, the reaction order $n$ was calculated as 0.9047. Based on the kinetic parameters obtained, the rate of bulk polymerization could be expressed as follows.

$$
\frac{\mathrm{d} \alpha}{\mathrm{d} t}=1.58 \times 10^{11} \exp \left(\frac{-8.277 \times 10^{4}}{R T}\right)(1-\alpha)^{0.9047}
$$

The rate of polymerization equation was used to compute $\mathrm{d} \alpha / \mathrm{d} t$ versus $T$ curves and comparisons with the experimentally obtained curves are shown in Fig. 10. The calculated value of $\mathrm{d} \alpha / \mathrm{d} t$ based on Eq. 11 was much higher than the experimental data. Evidently, the nth-order reaction is not able to accurately describe the bulk polymerization of DHA-DG-AC.

\subsubsection{Autocatalytic kinetic model}

The kinetic parameters of the bulk polymerization of DHA-DG-AC were obtained by the method of Malek on kinetic analysis. The apparent activation energy $E_{\mathrm{a}}$ was obtained by the isoconversional method and the logarithmic form of the kinetic Eq. 4.

$$
\ln \frac{\mathrm{d} \alpha}{\mathrm{d} t}=\ln [A \mathrm{f}(\alpha)]-\frac{E_{\mathrm{a}}}{R T}
$$

The apparent activation energy $E_{\mathrm{a}}$ can be calculated by 


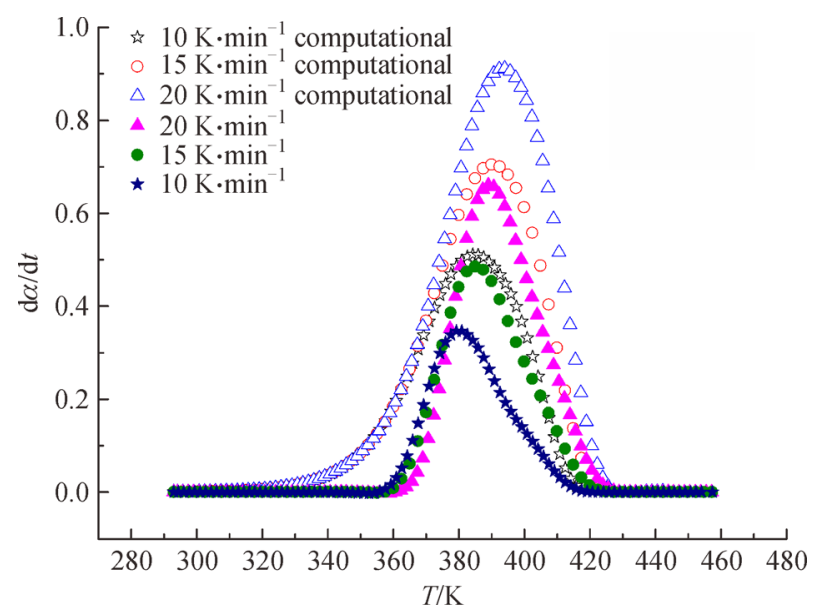

Fig. 10 Comparison of computational data and experimental data. $\mathrm{d} \alpha / \mathrm{d} t$, the rate of polymerization; $T$, the reaction temperature.

plotting of $\ln (\mathrm{d} \alpha / \mathrm{d} t)$ versus $1 / T_{\mathrm{p}}$ at different conversions as shows in Fig. 11.

As shown in Fig. 12, $E_{\mathrm{a}}$ increased with the conversion due to the decreased mobility of the reactive group ${ }^{[25]} . E_{\mathrm{a}}$ obtained a value of $95.73 \mathrm{~kJ} \cdot \mathrm{mol}^{-1}$.

There are two special functions needed, $\mathrm{y}(\alpha)$ and $\mathrm{z}(\alpha)$, to find an appropriate kinetic model ${ }^{[36]} \cdot \mathrm{y}(\alpha)$ and $\mathrm{z}(\alpha)$ are described as follows:

$$
\begin{gathered}
\mathrm{y}(\alpha)=\frac{\mathrm{d} \alpha}{\mathrm{dt}} \exp (u) \\
u=\frac{E_{\mathrm{a}}}{R T} \\
\mathrm{z}(\alpha)=\pi(u)\left(\frac{\mathrm{d} \alpha}{\mathrm{d} t}\right) \frac{T}{\beta}
\end{gathered}
$$

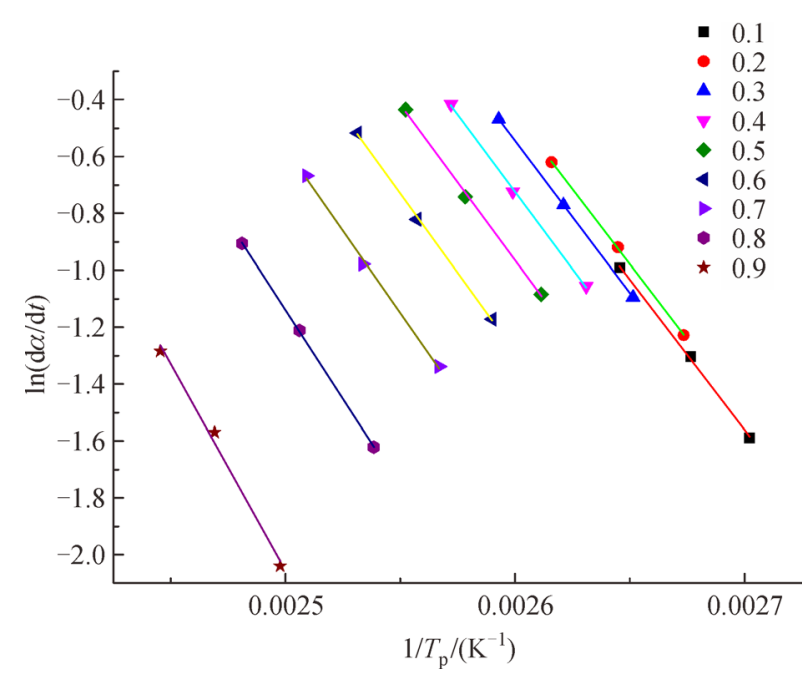

Fig. 11 Plots of $\ln (\mathrm{d} \alpha / \mathrm{d} t)$ versus $1 / T_{\mathrm{p}}$ at different conversions. $\mathrm{d} \alpha / \mathrm{d} t$, the rate of polymerization; $T_{\mathrm{p}}$, the DSC peak exotherm.

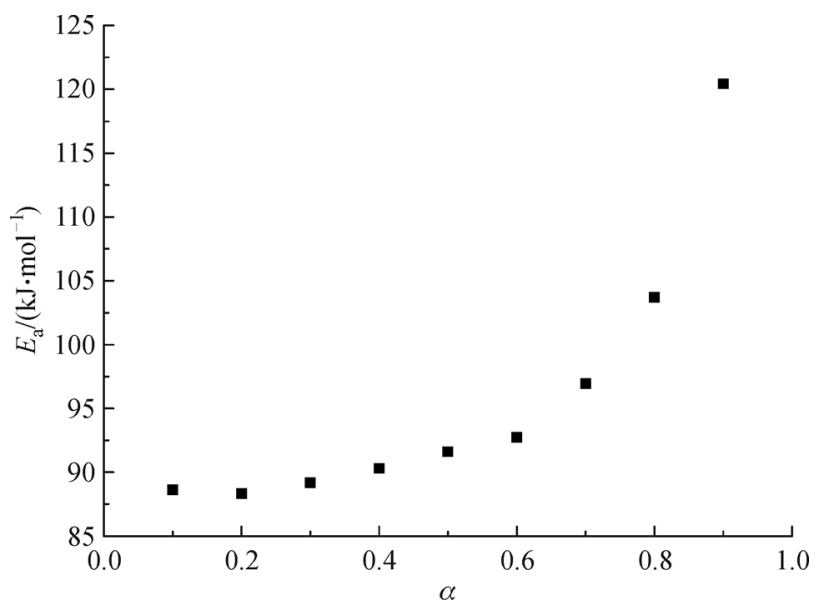

Fig. 12 The apparent activation energy $E_{\mathrm{a}}$ at different conversions $\alpha$

$$
\pi(u)=\frac{u^{3}+18 u^{2}+88 u+96}{u^{4}+20 u^{3}+120 u^{2}+240 u+120}
$$

The values of $\mathrm{y}(\alpha)$ and $\mathrm{z}(\alpha)$ were normalized within the range 0 to 1 . From Figs. 13 and $14, \alpha_{\mathrm{M}}$ and $\alpha_{\mathrm{p}}{ }^{\infty}$ are obtained and correspond to the max values of $\mathrm{y}(\alpha)$ and $z(\alpha)$, respectively. Based on Fig. 15 and Table 1, it is evident that the value of $\alpha_{\mathrm{M}}$ was lower than the value of $\alpha_{\mathrm{p}}{ }^{\infty}$, while $\alpha_{\mathrm{p}}{ }^{\infty}$ was less than 0.632. So the model of Sestak-Berggren, Eq. 17 was the most appropriate.

$$
\mathrm{f}(\alpha)=\alpha^{m}(1-\alpha)^{n}
$$

where $m, n$ refer to the the reaction order. The kinetic parameters are calculated by Eqs. 18 and 19.

$$
\begin{gathered}
\ln \left[\frac{\mathrm{d} \alpha}{\mathrm{d} t} \exp (u)\right]=\ln A+\ln \left[\alpha^{\mathrm{p}}(1-\alpha)\right] \\
\mathrm{p}=\frac{m}{n}=\frac{\alpha_{\mathrm{M}}}{1-\alpha_{\mathrm{M}}}
\end{gathered}
$$

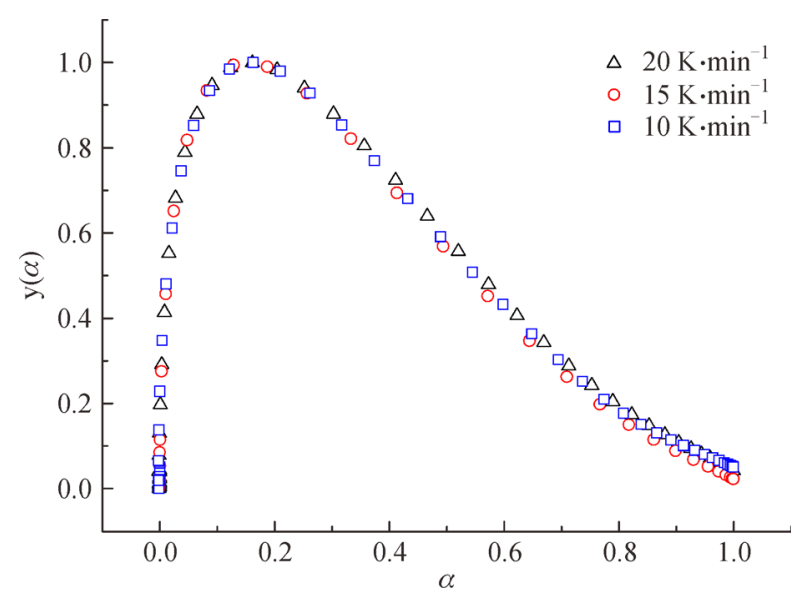

Fig. 13 Plots of $\mathrm{y}(\alpha)$ versus $\alpha . \mathrm{y}(\alpha)$, special function; $\alpha$, the conversion. 


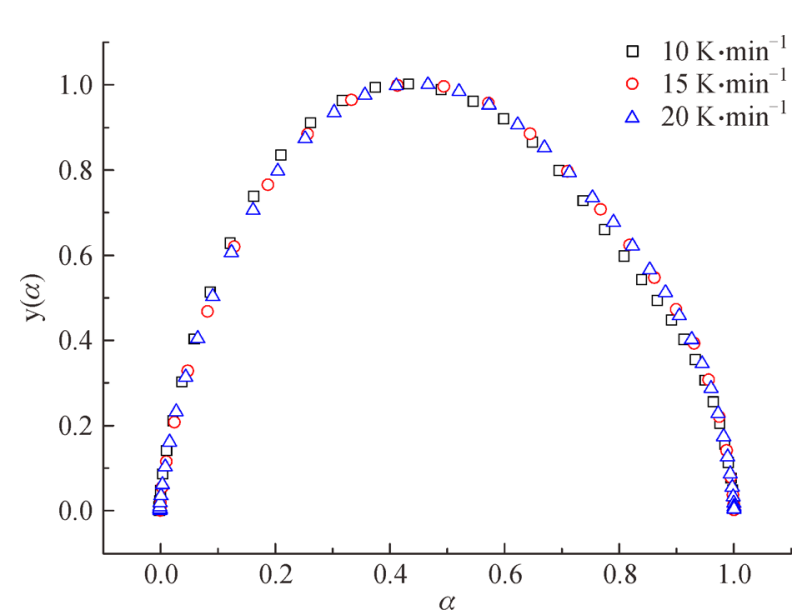

Fig. 14 Plots of $z(\alpha)$ versus $\alpha . z(\alpha)$, special function; $\alpha$, the conversion.

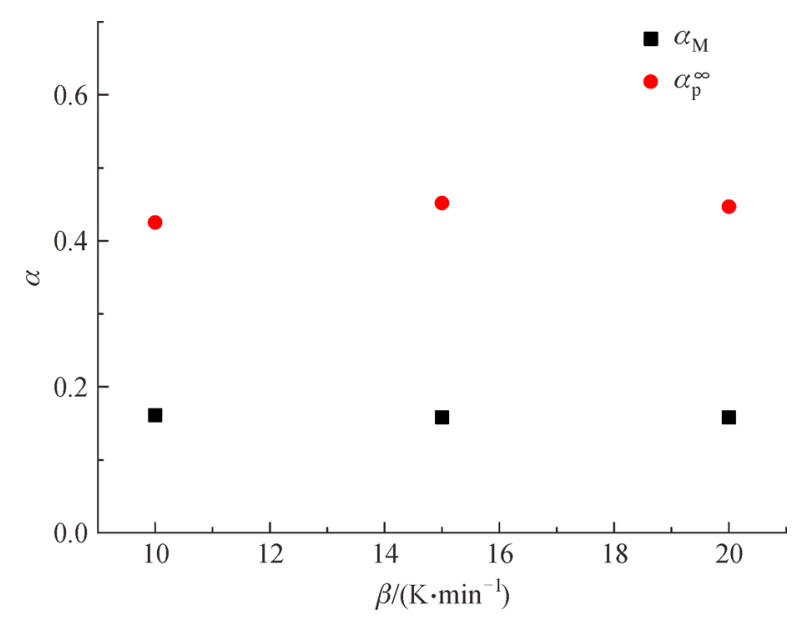

Fig. 15 The value of $\alpha_{\mathrm{M}}$ and $\alpha_{\mathrm{p}}{ }^{\infty}$. $\alpha_{\mathrm{M}}$, the maxima of $\mathrm{y}(\alpha)$; $\alpha_{\mathrm{p}}{ }^{\infty}$, the maxima of $\mathrm{z}(\alpha) ; \beta$, the heating rate; $\alpha$, the conversion.

Table 1 Empirical expressions of different kinetic models

\begin{tabular}{lc}
\hline Model & $f(\alpha)$ \\
\hline Šesták-Berggren & $\alpha^{n}(1-\alpha)^{n}$ \\
Johnson-Mehl-Avrami & $n(1-\alpha)[-\ln (1-\alpha)]^{1-1 / n}$ \\
Reaction order & $(1-\alpha)^{n}$ \\
2D-diffusion & $1 /[-\ln (1-\alpha)]$ \\
Jander equation & $(3 / 2)(1-\alpha)^{3 / 2}\left[1-(1-\alpha)^{1 / 3}\right]^{-1}$ \\
Ginstling-Brounshtein & $(3 / 2)\left[(1-\alpha)^{-1 / 3}-1\right]^{-1}$ \\
\hline
\end{tabular}

The plots of $\ln [(\mathrm{d} \alpha / \mathrm{d} t) \exp (u)]$ versus $\ln \left[\alpha^{\mathrm{p}}(1-\alpha)\right]$ are shown in Fig. 16. The values of $m, n$ and $A$ were obtained from the slope, the intercept and Eq. 19 listed in Table 2. So the kinetic equation of bulk polymerization is described in Eq. 20.

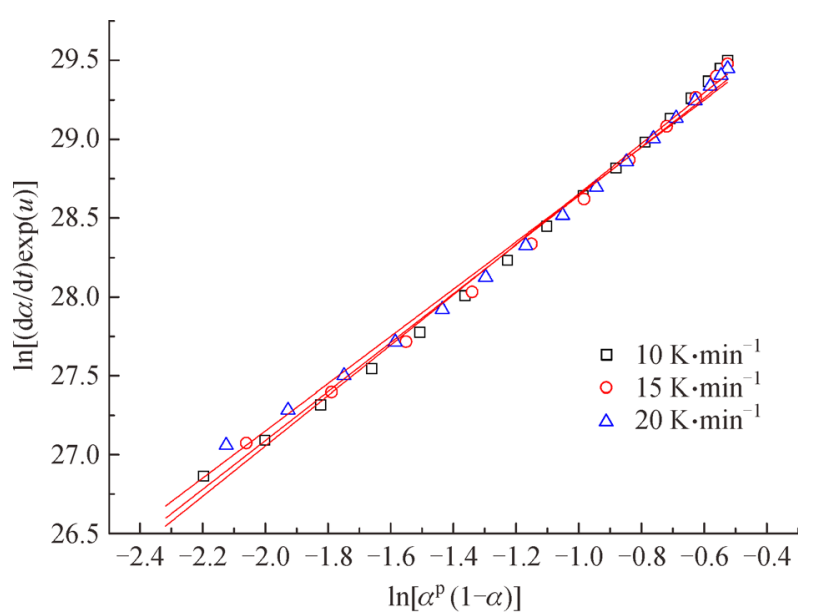

Fig. 16 Plots of $\ln [(\mathrm{d} \alpha / \mathrm{d} t) \exp (u)]$ versus $\ln \left[\alpha^{\mathrm{p}}(1-\alpha)\right]$. $u$, reduced activation energy; $\mathrm{d} \alpha / \mathrm{d} t$, the rate of polymerization; $\alpha$, the conversion.

Table 2 The value of $m, n, A$ at different heating rates

\begin{tabular}{lccc}
\hline$\beta /\left(\mathrm{K} \cdot \mathrm{min}^{-1}\right)$ & $A$ & $m$ & $n$ \\
\hline 10 & $1.24 \times 10^{13}$ & 0.2814 & 1.4977 \\
15 & $1.30 \times 10^{13}$ & 0.2914 & 1.5509 \\
20 & $1.38 \times 10^{13}$ & 0.3003 & 1.5980 \\
Average & $1.30 \times 10^{13}$ & 0.2910 & 1.5489 \\
\hline
\end{tabular}

$$
\begin{aligned}
\frac{\mathrm{d} \alpha}{\mathrm{d} t}= & 1.305 \times 10^{13} \\
& \times \exp \left(\frac{-9.573 \times 10^{4}}{R T}\right) \alpha^{0.2910}(1-\alpha)^{1.5489}
\end{aligned}
$$

Figure 17 shows comparison of computational data obtained from Eq. 20 and experimental DSC curves. It can be seen that the autocatalytic kinetic model well described the bulk polymerization of DHA-DG-AC.

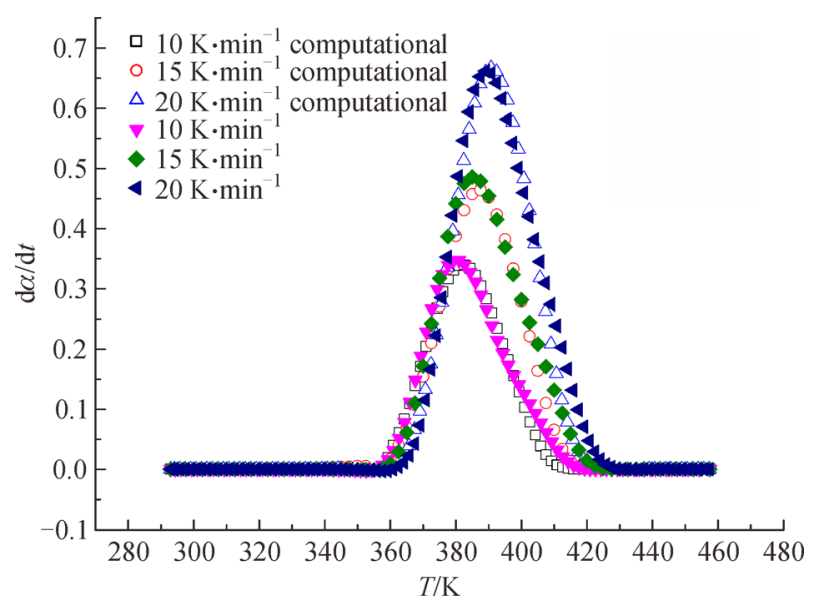

Fig. 17 Comparison of computational data and experimental data. $\mathrm{d} \alpha / \mathrm{d} t$, the rate of polymerization; $T$, the reaction temperature. 


\section{Conclusions}

DHA-DG-AC was successfully synthesized and characterized by FT-IR spectra, MS, ${ }^{13} \mathrm{C}$ NMR and ${ }^{1} \mathrm{H}$ NMR spectra. The kinetics of the bulk polymerization of DHA-DG-AC were studied by DSC in the non-isothermal mode. Two kinds of kinetic model: nth-order and autocatalytic were investigated. It was established that the autocatalytic kinetic model was the most suitable model for description of the bulk polymerization of DHA-DG-AC, and the value of $E_{\mathrm{a}}$ was $95.73 \mathrm{~kJ} \cdot \mathrm{mol}^{-1}$. DHA-DG-AC is a naturallyderived polymerizable monomer.

Supplementary materials The online version of this article at $\mathrm{http}: / / \mathrm{dx}$. doi.org/10.15302/J-FASE-2016115 contains supplementary material (Fig. S1).

Acknowledgements This study was supported by the National Natural Science Foundation of China (31470597).

Compliance with ethics guidelines Haibo Zhang, Yanping Yang, He Liu, Jie Song, Shibin Shang, and Zhanqian Song declare that they have no conflict of interest or financial conflicts to disclose.

This article does not contain any studies with human or animal subjects performed by any of the authors.

\section{References}

1. Corma A, Iborra S, Velty A. Chemical routes for the transformation of biomass into chemicals. Chemical Reviews, 2007, 107(6): 24112502

2. Kong X, Qi H, Curtis J M. Synthesis and characterization of highmolecular weight aliphatic polyesters from monomers derived from renewable resources. Journal of Applied Polymer Science, 2014, 131(15): 40579

3. Williams C K, Hillmyer M A. Polymers from renewable resources: a perspective for a special issue of polymer reviews. Polymer Reviews, 2008, 48(1): 1-10

4. Yao K, Tang C. Controlled polymerization of next-generation renewable monomers and beyond. Macromolecules, 2013, 46(5): 1689-1712

5. Yadav B K, Gidwani B, Vyas A. Rosin: recent advances and potential applications in novel drug delivery system. Journal of Bioactive and Compatible Polymers: Biomedical Applications, 2015: 1-16

6. Wilbon P A, Chu F, Tang C. Progress in renewable polymers from natural terpenes, terpenoids, and rosin. Macromolecular Rapid Communications, 2013, 34(1): 8-37

7. Gonis G, Slezak F B, Lawson N E. Preparation of maleopimaric acid. Industrial \& Engineering Chemistry Product Research and Development, 1973, 12(4): 326-327

8. Lee J S, Hong S I. Synthesis of acrylic rosin derivatives and application as negative photoresist. European Polymer Journal, 2002, 38(2): 387-392

9. Ma Q, Liu X, Zhang R, Zhu J, Jiang Y. Synthesis and properties of full bio-based thermosetting resins from rosin acid and soybean oil: the role of rosin acid derivatives. Green Chemistry, 2013, 15(5): $1300-1310$

10. Sinha Roy S, Kundu A K, Maiti S. Polymers from renewable resources-13. Polymers from rosin acrylic acid adduct. European Polymer Journal, 1990, 26(4): 471-474

11. Halbrook N J, Lawrence R V. Separation of fumaropimaric acid from fumaric-modified rosin products. US Patent 2889362, 1956

12. Aldrich $P$ H. Process for separation of rosin adducts from mixtures with rosin. US Patent 3562243, 1971

13. Atta A M, Elsaeed A M, Farag R K, El-Saeed S M. Synthesis of unsaturated polyester resins based on rosin acrylic acid adduct for coating applications. Reactive \& Functional Polymers, 2007, 67(6): 549-563

14. Deng L, Ha C, Sun C, Zhou B, Yu J, Shen M, Mo J. Properties of bio-based epoxy resins from rosin with different flexible chains. Industrial \& Engineering Chemistry Research, 2013, 52(37): 13233-13240

15. Jin J F, Chen Y L, Wang D N, Hu C P, Zhu S, Vanoverloop L, Randall D. Structures and physical properties of rigid polyurethane foam prepared with rosin-based polyol. Journal of Applied Polymer Science, 2002, 84(3): 598-604

16. Xu X, Shang S, Song Z, Cui S. Preparation and characterization of rosin-based waterborne polyurethane from maleopimaric acid polyester polyol. BioResources, 2011, 6(3): 2460-2470

17. Bicu I, Mustata F. Polymers from a levopimaric acid-acrylonitrile Diels-Alder adduct: synthesis and characterization. Journal of Polymer Science Part A: Polymer Chemistry, 2005, 43(24): 63086322

18. Mustata F, Bicu I. A novel route for synthesizing esters and polyesters from the Diels-Alder adduct of levopimaric acid and acrylic acid. European Polymer Journal, 2010, 46(6): 13161327

19. Wilbon P A, Chu F, Tang C. Progress in renewable polymers from natural terpenes, terpenoids, and rosin. Macromolecular Rapid Communications, 2013, 34(1): 8-37

20. Zheng Y, Yao K, Lee J, Chandler D, Wang J, Wang C, Chu F, Tang C. Well-defined renewable polymers derived from gum rosin. Macromolecules, 2010, 43(14): 5922-5924

21. Atta A M, El-Saeed S M, Farag R K. New vinyl ester resins based on rosin for coating applications. Reactive \& Functional Polymers, 2006, 66(12): 1596-1608

22. Liu B, Nie J, He Y. From rosin to high adhesive polyurethane acrylate: synthesis and properties. International Journal of Adhesion and Adhesives, 2016, 66: 99-103

23. Do H S, Park J H, Kim H J. Synthesis and characteristics of photoactive-hydrogenated rosin epoxy methacrylate for pressure sensitive adhesives. Journal of Applied Polymer Science, 2009, 111 (3): 1172-1176

24. Roşu D, Caşcaval C N, Mustată F, Ciobanu C. Cure kinetics of epoxy resins studied by non-isothermal DSC data. Thermochimica Acta, 2002, 383(1-2): 119-127

25. Boey F Y C, Qiang W. Experimental modeling of the cure kinetics of an epoxy-hexaanhydro-4-methylphthalicanhydride (MHHPA) system. Polymer, 2000, 41(6): 2081-2094

26. Um M K, Daniel I M, Hwang B S. A study of cure kinetics by the use of dynamic differential scanning calorimetry. Composites 
Science and Technology, 2002, 62(1): 29-40

27. Bera O, Pavličević J, Jovičić M, Stoiljković D, Pilić B, Radičević R. The influence of nanosilica on styrene free radical polymerization kinetics. Polymer Composites, 2012,33(2): 262-266

28. Vilas J L, Laza J M, Garay M T, Rodríguez M, León L M. Unsaturated polyester resins cure: kinetic, rheologic, and mechanical - dynamical analysis. I. Cure kinetics by DSC and TSR. Journal of Applied Polymer Science, 2001, 79(3): 447-457

29. Zhang G, Du S, Wang J, Wang X. Differential scanning calorimetric study on free-radical polymerization of gem-dinitroalkyl acrylates and methacrylate. Journal of Thermal Analysis and Calorimetry, 2009, 95(2): 433-436

30. Cui Y, Rao X, Shang S, Song J, Gao Y. Synthesis and antibacterial activity of oxime ester derivatives from dehydroabietic acid. Letters in Drug Design \& Discovery, 2013, 10(2): 102-110
31. Malek J. Kinetic analysis of crystallization processes in amorphous materials. Thermochimica Acta, 2000, 355(1-2): 239-253

32. Park B D, Riedl B, Hsu E W, Shields J. Differential scanning calorimetry of phenol-formaldehyde resins cure-accelerated by carbonates. Polymer, 1999, 40(7): 1689-1699

33. Montserrat S, Malek J. A kinetic analysis of the curing reaction of an epoxy resin. Thermochimica Acta, 1993, 228: 47-60

34. Kissinger H E. Reaction kinetic in differential thermal analysis. Analytical Chemistry, 1957, 29(11): 1702-1706

35. Crane L W, Dynes P J, Kaelble D H. Analysis of curing kinetic in polymer composites. Journal of Polymer Science. Polymer Letters Edition, 1973, 11(8): 533-540

36. Senum G I, Yang R T. Rational approximations of the integral of the Arrhenius function. Journal of Thermal Analysis, 1977, 11(3): 445447 